\title{
WEIRD FICTION IN BRITAIN 1880-1939 (2018), DE JAMES MACHIN
}

Ana Resende (UFF)

Recebido em 20 abr 2020. Ana Resende é Mestranda em Estudos de Literatura

Aprovado em 23 mai 2020. na Universidade Federal Fluminense (UFF), sob orientação do Prof. Dr. André Cardoso. 
Weird Fiction in Britain (1880-1939), de James Machin, publicado em 2018 na coleção "Palgrave Gothic", e ainda sem tradução para o português, é um livro ambicioso em seu escopo ao propor uma análise de como os "tentáculos" da ficção weird $^{1}$, costumeiramente associada às revistas pulp norte-americanas do início do século $X X$ e, em particular, à revista Weird Tales, se estendem até um local

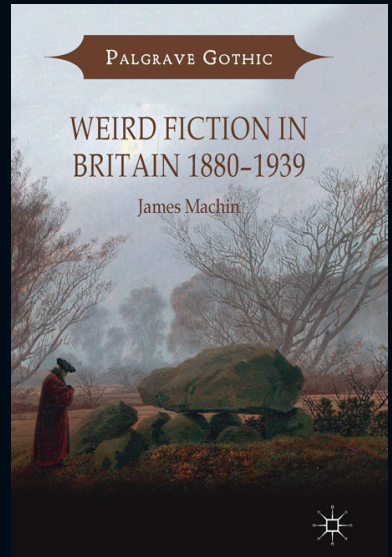
mais distante geograficamente e um período bem anterior, a saber, a Inglaterra de fim do século XIX. Nesta proposta, Machin se baseia nos trabalhos de S. T. Joshi e de China Miéville, para quem haveria uma "tradição" da ficção weird, que teria se iniciado em 1880 e iria até 1940, e que se opõe à perspectiva dos antologistas Ann e Jeff VanderMeer, para quem a ficção weird coincidiria com a criação da revista Weird Tales e com o círculo de autores formado em torno de H. P. Lovecraft.

A pesquisa de Machin também se insere numa tradição crítica e historiográfica que busca explorar a relação entre a alta literatura e a literatura popular. Podemos destacar, em língua inglesa, o trabalho pioneiro de Talia Schaffer, nos anos 2000, sobre a ficção popular de Ouida e sua influência na decadência literária inglesa, além das pesquisas de David Weir, Brian Stableford e, mais recentemente, Kirsten MacLeod e Roger Luckhurst, e, ainda, em

1 Aqui usarei os termos "weird" e "ficção weird" por concordar com Alexander Meireles, em seu artigo sobre a "Ficção Weird", publicado no Dicionário Digital do Insólito Ficcional (e-DDIF), que a tradução do termo em português faz com que se percam as várias dimensões da palavra em inglês. 
língua portuguesa, temos o artigo "Ecos da Pulp Era no Brasil: o Gótico e o Decadentismo em Gastão Cruls", de 2013, no qual seu autor, Júlio França, sugere uma possibilidade de leitura de algumas obras de autores brasileiros (incluindo autores canônicos como Érico Veríssimo e Guimarães Rosa), aproximando-os da literatura popular ao estilo das revistas pulp norte-americanas.

No entanto, na introdução e ao longo do restante do livro, James Machin tem um desafio: responder à pergunta "o que exatamente é o weird?", apontando para a complexidade do termo, que já era usado desde a última década do século XIX, mas sem muita precisão. No discurso literário finissecular, o uso do termo "weird" era comumente considerado sinônimo de "medonho", "perverso", "inquietante", "estranho", "nocivo", "horrível", "sobrenatural" e, algumas vezes, até "repulsivo".

E o próprio H. P. Lovecraft, em seu ensaio sobre o Horror Sobrenatural em Literatura, de 1927, parece definir o conto weird por aquilo que ele não é, em vez de dizer o que é: o conto weird tem "algo mais do que assassinatos secretos, ossos ensanguentados ou um vulto coberto com lençol, retinindo correntes $^{2 \prime \prime}$ (LOVECRAFT, 2013, posição 368). Embora não devesse ser confundido com contos góticos nem, muito menos, com histórias de fantasmas vitorianas, nunca houve regras estabelecidas para o conto weird. Em entrevista acerca do livro Weird Fiction in Britain (1880-1939), James Machin descreve algumas características dessa modalidade:

Fiç̧ão que provoca e envolve um medo mais conceitual do que o precipitado por ameaças à 2 Todos os trechos de obras indicadas em língua estrangeira nas referências foram traduzidos por mim. 
segurança física ou por repulsa direta. Além disso, parece haver algo próximo a um consenso no sentido de que é um modo, e não um gênero - algo que perpassa os gêneros. Embora, sem dúvida, esteja mais intimamente relacionado ao horror, também se associa ao numinoso. Eu também acho que a falta de fechamento narrativo é um dos seus identificadores frequentes. (MACHIN, 2019)

O livro de Machin se divide em quatro capítulos: "O Weird Fin-De-Siècle e Depois"; "Shiel, Stenbock, Gilchrist e Machen"; "Buchan" e "Weird Tales e a Decadência Pulp". No capítulo "O Weird Fin-De-Siècle e Depois", o autor explora a emergência do conto como forma literária e da ficção decadente em língua inglesa no fim do século XIX, concentrando-se no termo "weird" como um termo literário e crítico, bem como em usos que o diferenciassem de outras expressões, como "sobrenatural", "estranho", "horror", além da ficção gótica. É interessante recordar aqui a proposta do autor, apresentada na introdução do livro:

Pode ser útil considerar o Weird como uma linha (ou um tentáculo!) movendo-se através de vários círculos em um diagrama de Venn de gênero. Aninhados nos círculos mais amplos do Realismo e do Fantástico, que se intersectam, estão a Ficção Científica (ou Romance Científico), o Gótico e o Horror e, menor ainda, talvez, a História de Fantasmas e uma infinidade de subdivisões aparentemente inesgotáveis. O Weird pode abrir caminho para todos. Para os propósitos deste livro, no entanto, é necessário selecionar o tipo de Weird no qual eu pretendo me concentrar; o tipo de ficção weird a partir da qual podemos compreender melhor o que é a ficção weird. (MACHIN, 2018, p.17) 
Mais adiante no capítulo, James Machin se propõe examinar - mercado editorial das últimas décadas do século XIX. Tradicionalmente, a ficção vitoriana era consumida e produzida em forma seriada e mensal, e em romances de três volumes que, devido aos preços elevados, circulavam em bibliotecas itinerantes. O progresso das tecnologias de impressão, influências estéticas estrangeiras, mudanças na publicidade e outros fatores econômicos desempenharam um papel importante na criação de um mercado para a ficção curta. No fim do século XIX, o conto tinha apelo popular e literário, e essas condições de produção e recepção levaram ao surgimento de obras muito mais implicadas no mercado. Nesse contexto, Machin não parece considerar problemática a ideia de que Edgar Allan Poe seja um dos "pais fundadores" do conto britânico junto com Robert Louis Stevenson (ao contrário de outros estudiosos da ficção curta da virada do século XIX) e, ao contrário, insiste no mérito da ficção de Poe ser mediada por várias preocupações, incluindo a questão dos diferentes públicos.

No capítulo "Shiel, Stenbock, Gilchrist e Machen", o autor se detém sobre a vida e a produção dos ingleses M. P. Shiel, R. Murray Gilchrist, Count Stenbock e Arthur Machen, que, para Brian Stableford, seriam "produtos definitivos da Decadência inglesa" (Apud MACHIN, 2018, p.101), mas também influentes escritores de ficção weird. Para Machin, as obras desses autores representariam uma síntese do decadentismo e de temas horroríficos e/ou sobrenaturais em forma de contos e, além disso, seriam reconhecidas pelos contemporâneos e pela crítica posterior como sendo produzidas por autores que recorriam ao modo weird. 
Ainda que hoje nomes como os de Count Stenbock (18601895) e M. P. Shiel (1865-1947) sejam pouco conhecidos, Machin pretende mostrar o quanto esses primeiros expoentes da ficção weird influenciaram a obra de Lovecraft e o quanto a ficção decadente inglesa e a ficção popular publicada nas revistas pulp compartilhariam certas atitudes e preocupações sociais finisseculares. E mesmo que esses autores já tivessem morrido ou abandonado em grande parte os excessos estilísticos da Decadência, sua influência continuou do outro lado do Atlântico, com a publicação de suas produções literárias nas revistas pulp das décadas de 20 e 30. Machin cita ainda as obras de R. Murray Gilchrist (1867-1917) e recorda que seus contos eram publicados no The Yellow Book, ao lado de textos de autores como Henry James e Kenneth Grahame. Apesar de esquecido, suas contribuições à literatura finissecular ainda são lembradas por especialistas em literatura decadente e ficção sobrenatural.

Se Stenbock e Gilchrist são autores genuinamente obscuros, Arthur Machen, o outro autor mencionado no capítulo, ocupa uma posição curiosa: por um lado, a crítica costuma chamálo de "o pai esquecido da ficção weird" (MACHIN, 2018, p.126); por outro, edições de seus contos são cada vez mais comuns, e sua influência na ficção weird talvez só seja menor do que a do próprio H. P. Lovecraft. Mas a "Decadência" de Machen era, antes, uma manifestação da herança comum de Edgar Allan Poe e de Robert Louis Stevenson do que uma influência do simbolismo francês, inclusive no que se refere ao modelo de uma ficção potencialmente comercial. O que leva o autor de Weird Fiction in Britain (1880-1939) a apontar, sem, no entanto, tirar conclusões 
desse fato, que mesmo após o julgamento e condenação de Oscar Wilde (este sim, um leitor da Decadência francesa) por sodomia, em 1895, publicações ligadas à ficção decadente, como The Yellow Book, continuaram a circular. Em 1896, nos sumários de suas quatro edições, era possível ler nomes como Henry James, Vernon Lee e Max Beerbohm.

Para mostrar a influência de Stevenson na principal obra de Arthur Machen, $O$ Grande Deus Pã, James Machin cita a conhecida entrada do diário do autor, na qual ele observa:

[Nós] devemos vincular nossas maravilhas a algum fato, base ou método científico ou pseudocientífico. Se Stevenson tivesse escrito sua grande obra-prima entre 1590 e 1650, o dr. Jekyll teria feito um pacto com o diabo; em 1886, o dr. Jekyll compra algumas drogas raras dos químicos de Bond Street. (Apud MACHIN, 2018, p.145)

Uma ressalva que se poderia fazer ao capítulo é quanto ao corpus analisado. Embora James Machin se proponha pensar a "tradição weird" entre os anos de 1880 e 1940, ou seja, entre as primeiras manifestações da ficção decadente em língua inglesa e o declínio das revistas pulp, ao selecionar os autores que pretende estudar, ele se baseia no recorte temporal feito por Brian Stableford, em The Dedalus Book of Decadence (Moral Ruins): "Os produtos mais intensamente escandalosos da Decadência inglesa podem ser encontrados em um pequeno grupo de coleções de contos, publicado entre 1893 e 1896" (Apud MACHIN, 2018, p.78).

Ao limitarem a decadência inglesa a um curto período da década de 1890 e a apenas cinco obras publicadas, Stableford e Machin ignoram também a presença feminina nos contos da 
decadência literária britânica e o pioneirismo de algumas dessas autoras, em particular, da inglesa Vernon Lee, de quem Brian Stableford reconhece a importância para a ficção decadente inglesa, ao lado de outros "exemplos notáveis": Arthur Machen, R. Murray Gilchrist e M. P. Shiel, no artigo "Haunted by the Pagan Past: an Introduction to Vernon Lee".

Como demonstrou Anthony Camara, em sua tese de doutorado, Dark Matter: British Weird Fiction and the Substance of Horror, 1880-1927, Vernon Lee certamente deveria figurar entre os "antecessores de Lovecraft" (CAMARA, 2013, p.16). Embora Lee não seja normalmente associada ao conto weird, Camara considera que seus contos, em particular, as histórias de Hauntings, coletânea publicada no ano de 1890, nos ajudam a entender como a ficção weird surgiu através de rupturas e modificações de tradições sobrenaturais anteriores, como as histórias de fantasmas vitorianas e o romance gótico.

O capítulo seguinte de Weird Fiction in Britain (1880-1939), "Buchan", se concentra em um escritor que, apesar da fama e da popularidade, não costuma ser considerado um autor de ficção weird. Para Machin, John Buchan seria um autor de transição entre a decadência literária finissecular e o emergente mercado das revistas pulp, no início do século XX; um autor para quem a ficção sempre constituiu um exercício comercial tanto quanto artístico, e para quem os dois aspectos não eram excludentes (um de seus livros mais famosos, The Thirty-Nine Steps, foi adaptado para o cinema por Alfred Hitchcock). No capítulo, Machin ressalta também como Buchan, colaborador frequente no The Yellow Book, estava ligado a um contexto mais amplo da ficção weird, que incluía, por 
exemplo, referências ao Oriente e ao paganismo, além da ficção de aventura colonial, associada a autores como H. Rider Haggard e Rudyard Kipling.

No capítulo que encerra o livro, "Weird Tales e Decadência Pulp", James Machin aborda o auge da ficção weird, que coincide com a criação da revista Weird Tales, argumentando que a revista pulp era parte de uma tradição existente e poderia ser considerada uma continuidade da decadência literária finissecular em pleno modernismo. O autor mostra como tanto no conteúdo produzido para a revista, que incluía uma variedade impressionante de textos, desde histórias populares e contos de Poe até reimpressões de autores como Sheridan Le Fanu, Arthur Machen, H. G. Wells, Arthur Conan Doyle e E. F. Benson, quanto na seção de "cartas aos editores" ("The Eyrie"), a comunidade formada em torno da Weird Tales se reconhecia mais por fazer parte de uma "tradição weird" do que propriamente pelo pioneirismo em uma nova forma literária.

Caberia aqui um comentário sobre o capítulo "Weird Tales e Decadência Pulp": é interessante ver como James Machin mostra mais do que rupturas, as semelhanças e continuidades entre a alta literatura e a literatura popular, em particular, a ficção weird. Mas tanto a decadência literária inglesa quando a ficção weird parecem emergir, mesmo de um ponto de vista "cultural", de uma crise linguística vitoriana, e em um estudo sobre os precursores da ficção weird a linguagem mereceria destaque, pois o uso que esses autores fazem dela, longe de ser mero beletrismo parece servir ao efeito que eles queriam criar. 
No caso de Lovecraft, por exemplo, tal como observa S. T. Joshi, na "Introdução" a The Call of Cthulhu and Other Weird Stories, o uso das catacreses, entre outras características, se adequaria ao tipo de efeito encantatório evocado, por isso, é importante recordar que "Lovecraft era quase sempre o mestre, e não o escravo, de seu estilo" (JOSHI, 1999, posição 252). Da mesma forma, o pesquisador Júlio França, em seu artigo sobre Gastão Cruls e as revistas pulp, mencionado anteriormente, refere-se à necessidade de estudarmos a linguagem desses autores não como defeitos de estilo, mas como características formais:

Assim, talvez, possamos descobrir que os barroquismos de linguagem de ambos os autores - o preciosismo de Cruls, as catacreses de Lovecraft - funcionam como um recurso formal que reforça a visão de mundo por eles sustentada. (FRANÇA, 2013, p.16)

No final do capítulo, Machin volta a citar Brian Stableford, agora em Glorious Perversity: The Decline and Fall of Literary Decadence, para quem os Estados Unidos, que não raro eram descritos como "o último lugar na Terra que ofereceria solo fértil para a Decadência" (Apud MACHIN, 2018, p.221), proporcionaram uma sobrevida a esta modalidade literária, com autores como Ambrose Bierce, Robert W. Chambers, Clark Ashton Smith e H. P. Lovecraft, que, junto com a revista Weird Tales, trouxe a Decadência "dos salões da Europa fin-desiècle para as movimentadas bancas de jornais dos Estados Unidos nos anos de 1920" (MACHIN, 2018, p.221) ao fazer "um uso extravagante, ainda que tardio, de tropos decadentes" (Apud MACHIN, 2018, p.221).

A degenerescência hereditária, que assombrava o imaginário da Decadência em língua inglesa no fim do século XIX, assumia, 
dessa forma, uma estranha perspectiva cósmica e tornava-se agora condição do universo.

\section{REFERÊNCIAS}

CAMARA, Anthony Christopher (2013). Dark Matter: British Weird Fiction and the Substance of Horror, 1880-1927. (Tese - Doutorado em Literatura Inglesa). Universidade da Califórnia. Los Angeles, p.226.

FRANÇA, Júlio (2013). “Ecos da Pulp Era no Brasil: o Gótico e o Decadentismo em Gastão Cruls". Terra Roxa e outras terras - Revista de Estudos Literários. 26, Dez. JOSHI, S. T. (1999) "Introduction". In: LOVECRAFT, H. P. The Call of Cthulu and Other Weird Stories. Nova York: Penguin Group. Edição do Kindle.

Lovecraft, H. P. (2013). The Annotated Supernatural Horror in Literature: Revised and Enlarged. Nova York: Hippocampus Press. Edição do Kindle.

MACHIN, James (2018). Weird Fiction in Britain 1880-1939. Cham: Palgrave Macmillan. ("Palgrave Gothic")

(2019). Weird Fiction [Entrevista concedida a] Jared Neuharth. In https://sites.utexas.edu/ransomcentermagazine/2019/04/01/weird-fiction/ Acesso em 16.Dez.2019.

MEIRELES, Alexander (s/d). "Ficção Weird". In: REIS, Carlos; ROAS, David; FURTADO, Filipe; GARCIA, Flávio; FRANÇA, Júlio (Editores). Dicionário Digital do Insólito Ficcional (e-DDIF). Rio de Janeiro: Dialogarts. In http://www. insolitoficcional.uerj.br/site/f/ficcao-weird/ Acesso em 16.Dez.2019.

STABLEFORD, Brian ( $\mathrm{s} / \mathrm{d}$ ). "Haunted by the Pagan Past: an Introduction to Vernon Lee". In http://www.infinityplus.co.uk/introduces/lee.htm cesso em 13.Jan.2020. 